\title{
Exploring Opportunities with Open Source GIS
}

\author{
Sandhya M C \\ Asst. Prof. Department of Civil Engineering \\ Ahmedabad Institute of Technology \\ Ahmedabad, Gujarat, India.
}

\begin{abstract}
There are many Commercial software available for various GIS Applications. These Software are very costly and making unaffordable for the General users. So we need an alternate option which is Economical, Feature rich \& similar Capabilities as that of Commercial ones. Such possibilities can be explored by Evaluating Open Source GIS software. Recently open source software start playing vital role in Industry, Academics and Research. Quantum GIS (QGIS) is most popular, leading and user friendly open source GIS software. It is very easy to use, extensible, and has a constantly growing community and user base. More and more Private users and organizations choose QGIS as their mainstream GIS software. Hence it is necessary to study the opportunities of this open source software as an alternative to the established proprietary software.
\end{abstract}

Keywords-GIS; QUANTUM GIS; POSTGIS; NEXTGIS.

\section{INTRODUCTION}

A Geographic Information System (GIS) is a system capable of Capturing, Storing, Editing, Managing, Displaying, Analyzing and Sharing data which is spatially referenced to the earth. GIS can be used in various fields such as Transportation, Logistics, History, Sales, Marketing, Planning, Management etc. etc.

There are many Commercial GIS software available for GIS applications such as ESRI's ArcGIS, Geomedia, MapInfo Professional, Global Mapper, manifold GIS, Small World, Bentley Map, Map viewer etc. ArcGIS is well-established commercial software in GIS industry. In the field of GIS open source software experienced a boost over last few years. GRASS, gvSIG, Open JUMP GIS, Quantum GIS (QGIS), uDig GIS, SPRING are open source Desktop GIS software. Geo Majas, GeoServer, MapFish, MapServer, Open Layers are some of the open source Software for web mapping.

Quantum GIS (QGIS) is most popular, leading and user friendly open source software. It is licensed under GNU public License. Anybody can download it and use freely. It works on windows, Linux and Mac platforms. A new mobile version is also developed for Android. There are plenty of supports, documents and tutorials available in QGIS for users. It can accept all types of data in different format and projections. It can perform different types of spatial analysis such as Terrain analysis, Hydrological Analysis, Network analysis etc.

Plugins in QGIS are written in Python or $\mathrm{C}++$ and this extends QGIS's capabilities. These plugins are written by developers and other independent users who wanted to extend the core functionality of this software. These plugins are available for all users, according to our needs we can install the appropriate plugins. There are more than 650 plugins available right now.

The Distribution and sharing of Geo-spatial data to a wider community play an important role in development. These data can be accessed by any sources Desktops, Laptops or mobiles through internet. Sharing and Dissemination of data offers possibilities to access right data at right time to make right kind of decisions. It provides communication between different stakeholders such as Government Authorities and Citizens, for proper Planning, Monitoring and Management of Resources.

GIS Cloud technology is an upgradation to traditional GIS which provides services to users across the globe. (Bhat et al., 2011). Technological advancement and easy access to the internet and necessity for publishing maps and sharing information widely have made WebGIS mandatory for many organizations today. (Elavazhagan and Vijayee, 2010). NextGIS Connect is a QGIS Plugin; this is a new cloud based technology for publishing maps online. In NextGIS Resource Page we can upload layers / Project and WebMap is created and is shown in a separate web browser. This web interface enables user to view the layers, its feature tables and descriptions. User can identify features, zoom in and out, perform query, search, check the coordinates of any location, measure Distance between any two locations, measure Area of any polygon, print the map and share the maps through any of the following social media networks Facebook, Twitter, Google Plus etc.

\section{OBJECTIVE}

The objective of this study is to explore the opportunities of Open Source Software QGIS in terms of its spatial analysis and web publishing capabilities.

- To provide a system that can be applied to a Road Network with the intension of finding out 'Optimal Path' (Shortest \& Fastest) between any two locations.

- To create a a user friendly 'WebMap Interface' with functionalities to visualize layers \& its feature table, description, attachments; Search and Identify features; Zoom in and out; Measure Distance \& Area; Share and Print the map Units. 


\section{STUDY AREA}

GUJARAT is taken as study area for this Research Study. Latitude spreads from of $22^{\circ} 10^{\prime}$ North to $24^{\circ} 50^{\prime}$ North and Longitude spreads from $68^{\circ} 40^{\prime}$ East to $74^{\circ} 40^{\prime}$ East.

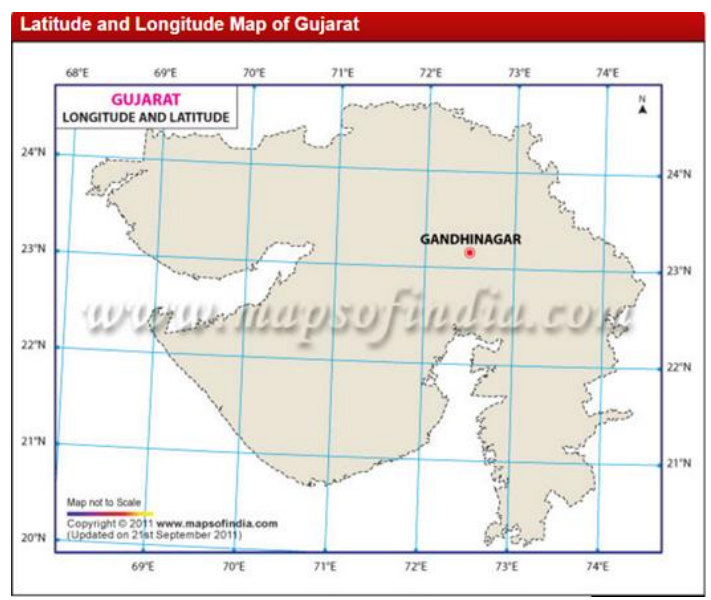

Fig. 1. Latitude and Longitude Map of Gujarat.

GUJARAT is one of the developed states of India. Gujarat is having plenty of Industries and other major infrastructures to boost the economy of the state. As per 2011 Census Gujarat's total Geographical area is 1, 96,024 square Kilometers and population of 60,383,628. And has 26 districts, 226 Talukas, 18618 villages and 242 towns.

Gandhinagar is the state capital having population of $1,391,753$. Ahmedabad is the commercial capital of Gujarat state. Ahmedabad is the most populated District in the state with 7.2 million people, and it also the 8th most populous district in India. Kachchh is the biggest district with 42,373.94 Square kilometers of area. The Dangs is the smallest District with an area of 1803.48 Square kilometers with Ahwa as the headquarters.

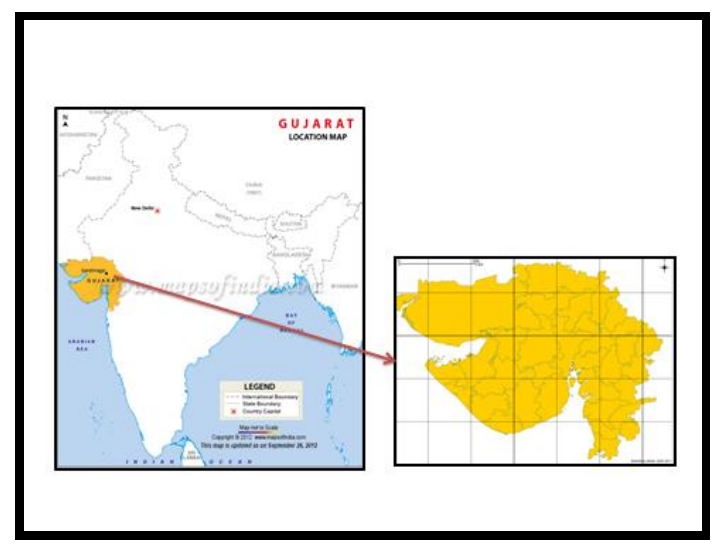

Fig. 2. Map of Gujarat.

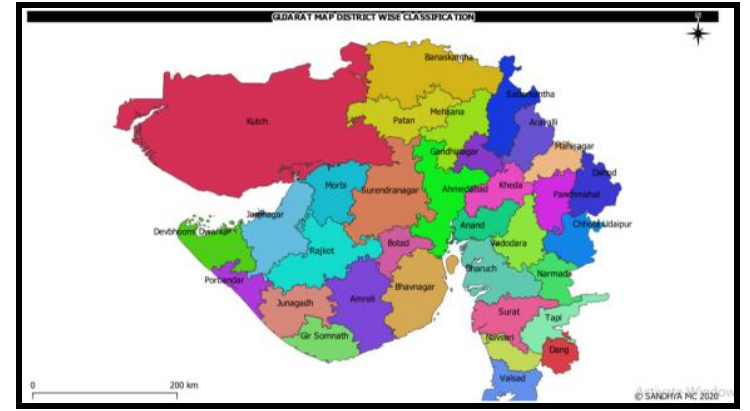

Fig. 3. District wise Classification Of Gujarat.

\section{DATA USED}

- Gujarat District Map

- District Demographic Data Table.

- Roads - State Highways(SH) \& National Highways (NH).

- Airports

- Sea Ports

- Agricultural Produce Market Committee (APMC)

- District Head Quarters

- Taluka Head Quarters

- GIDC - Gujarat Industrial Development Corporation, Special Economic Zones (SEZ)

\begin{tabular}{|c|l|l|}
\hline Sl.no & \multicolumn{1}{|c|}{ Name } & \multicolumn{1}{c|}{ Type } \\
\hline $\mathbf{1}$ & Districts & Polygon \\
\hline $\mathbf{2}$ & Road Networks & Line \\
\hline $\mathbf{3}$ & Airports,Sea Ports & Points \\
\hline $\mathbf{4}$ & APMC's & Points \\
\hline $\mathbf{5}$ & District Head Quarters & Points \\
\hline $\mathbf{6}$ & Taluka Head Quarters & Points \\
\hline $\mathbf{7}$ & GIDC & Points \\
\hline $\mathbf{8}$ & District Data Table & Excel \\
\hline
\end{tabular}

\section{SOFTWARES \& TOOLS USED}

- QGIS Desktop 2.18 Las Palmas

- Open Geo Suite 3.0 from Boundless

- POSTGIS

- Road Graph

- AequilibraE

- NextGIS

\begin{tabular}{|l|l|l|}
\hline Sl.no & Software/ Tools Used & \multicolumn{1}{|c|}{ Purpose of use } \\
\hline 1 & POSTGIS & Spatial Database Creation \\
\hline 2 & $\begin{array}{l}\text { QGIS Desktop 2.18 Las } \\
\text { Palmas }\end{array}$ & $\begin{array}{l}\text { Map creation, Spatial } \\
\text { Analysis, WebMap Creation }\end{array}$ \\
\hline 3 & AequilibraE & Network Preparation \\
\hline 4 & Road Graph & Shortest Path, Fastest Path \\
\hline 5 & NextGIS & $\begin{array}{l}\text { WebGIS Resource Page, } \\
\text { WebMap Creation }\end{array}$ \\
\hline 6 & MS Excel & Comparison Sheets, Tables \\
\hline 7 & MS word & Reports \\
\hline
\end{tabular}

\section{METHODOLOGY}

The detailed methodology adopted for this work to achieve above mentioned objective is explained below. 


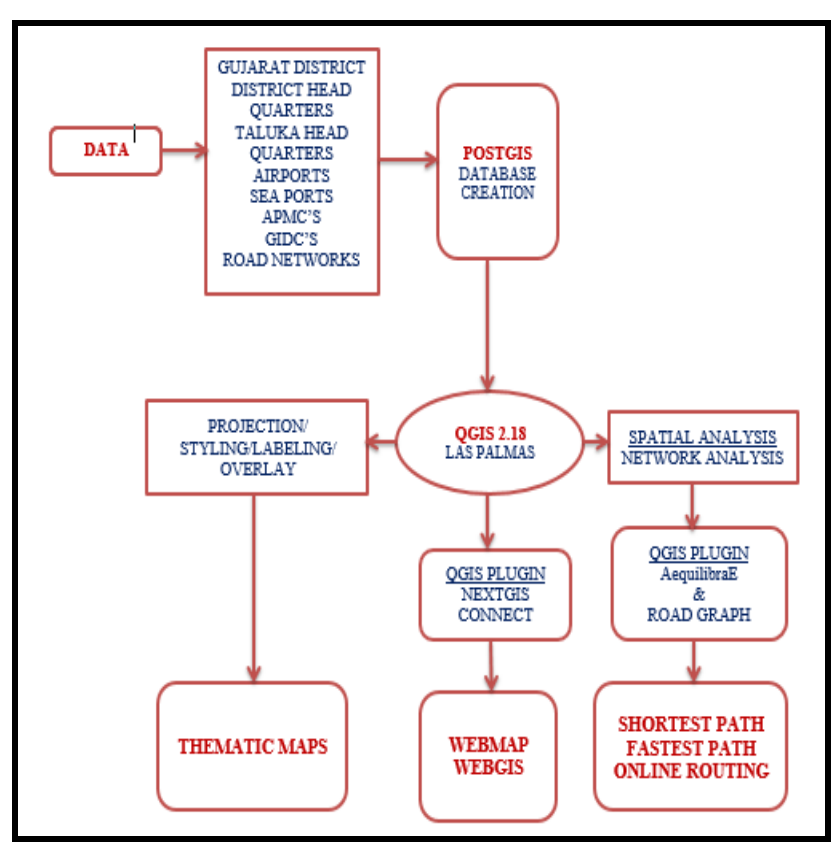

Fig. 4. Methodology.

\section{PREPARATION OF DATABASE, MAPS, ANALYSIS \& SHARING}

\section{A. Database Creation}

In pgAdmin III, new server connection is done. Under that server connection a new data base is created. After successful POSTGIS Database connection, import all the shape files to the database with proper SRID using pgShapeLoader.

\section{B. Thematic Maps Preparation.}

\section{- GUJARAT District MAP}

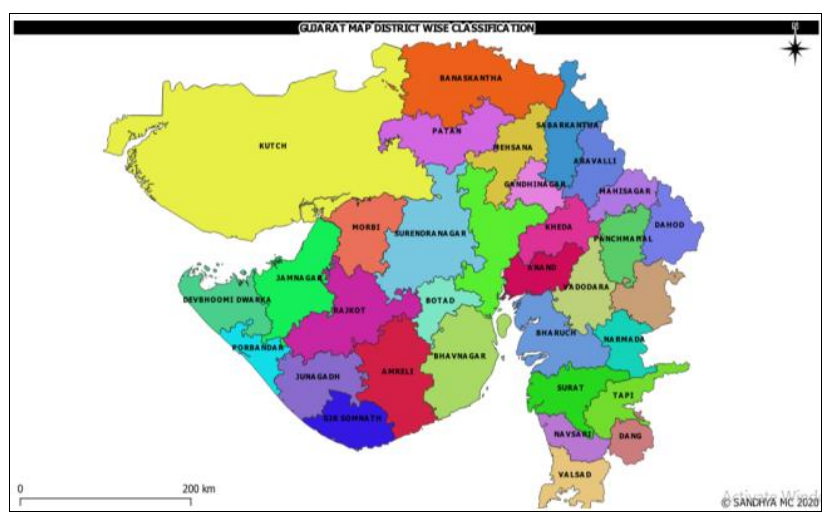

Fig. 5. District wise Classification Of Gujarat.

\section{- Road Networks \& Infrastructure}

The state of Gujarat is having a huge Road Network Comprising National Expressway, National Highways, State Highways, Major District Roads, Other District Roads, Village Roads and Other Roads.

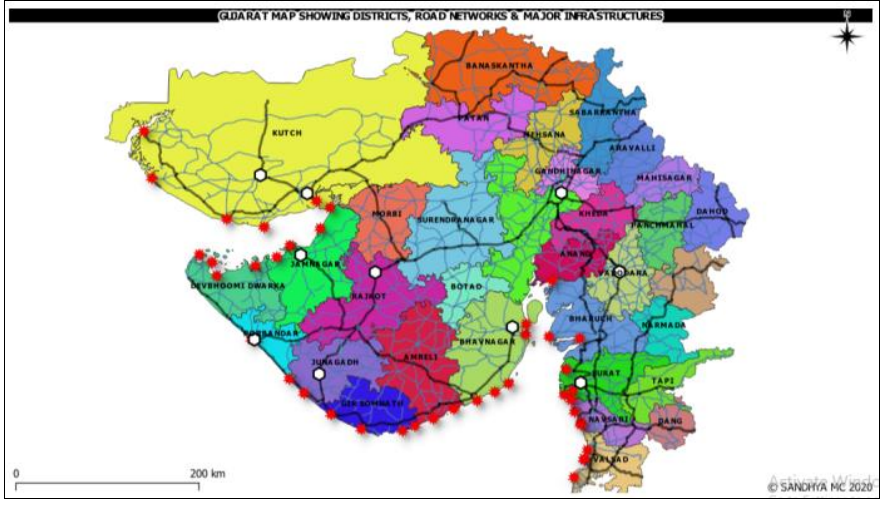

Fig. 6. Map showing infrastructure facilities of Gujarat.

For this study only State Highways and National Highways are considered. The State covers approximately $6000 \mathrm{kms}$. Of National Highways and 19,000 kms of State Highways.

\section{Spatial Network analysis}

\section{- AEQUILIBRAE}

India has one of the largest connectivity in terms of Road networks in the world. These Road Networks have been there from ancient time, but the usage of these roads is significantly increased recently. Geographic Information System (GIS) technology has recently seen development in the areas of Network and Transportation Analysis. A fundamental problem in Network analysis is the computation of shortest paths between any two randomly chosen locations within a network. This study provides a system which can be applied to any type of Road Network with the intension of providing optimal path from one point to another.

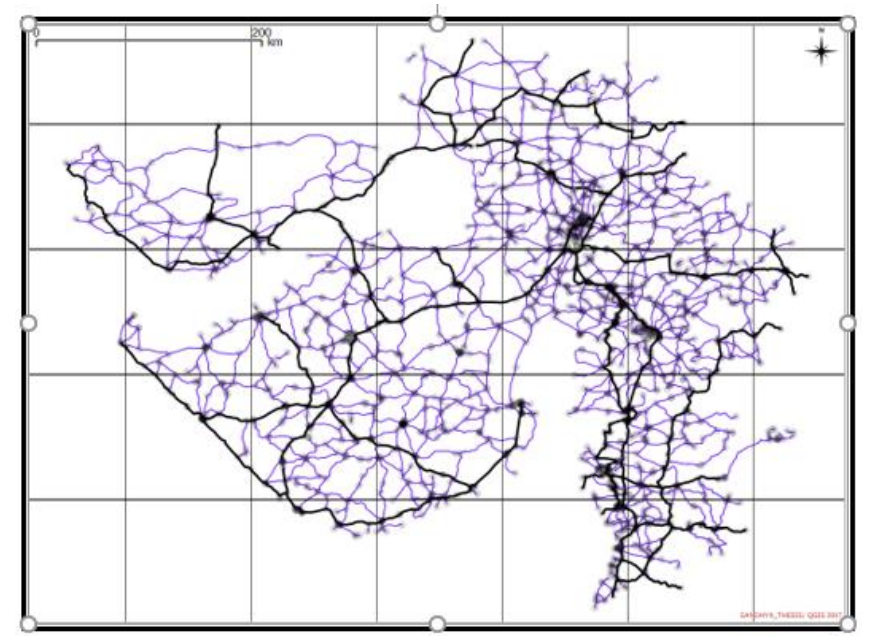

Fig. 7. Network line layer \& Node layer 


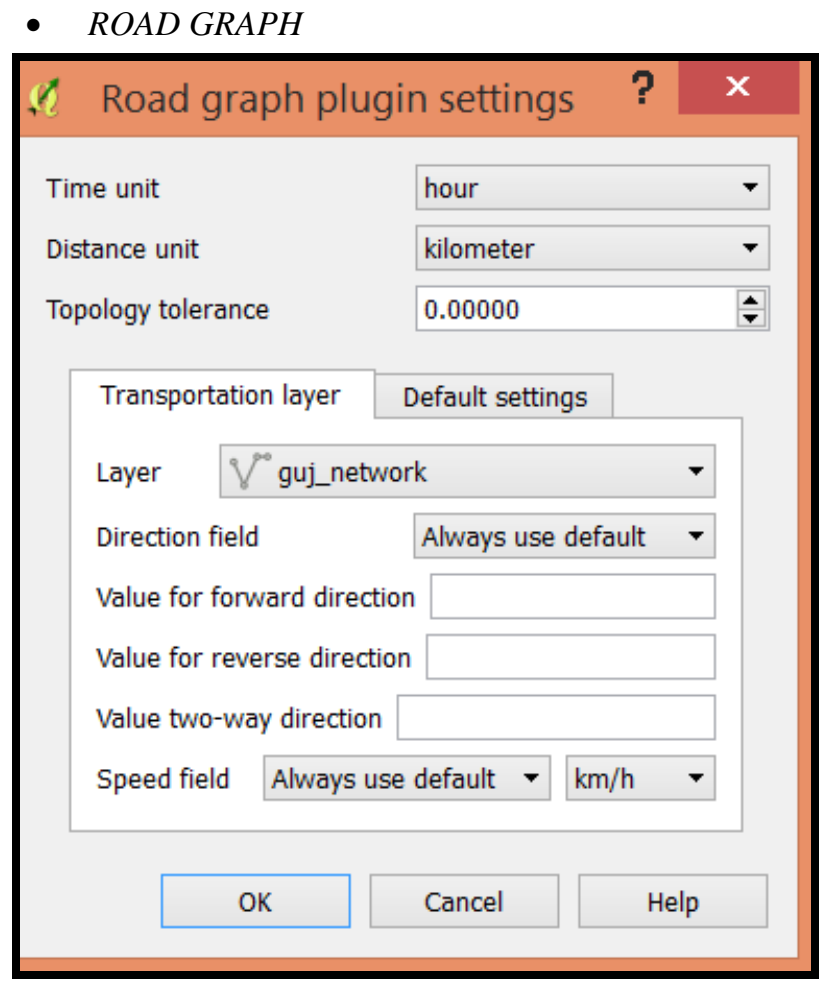

Fig. 8. Road Graph Plugin

\section{- $\quad$ SHORTEST PATH}

The common application of Network analysis is to find the Shortest Path on a Road Network. Finding the shortest route from one location to another location through a network is very much useful in case of emergencies, during holidays / business trips and for transportation planners. To carry out such type of analysis it is very important to prepare an appropriate network.

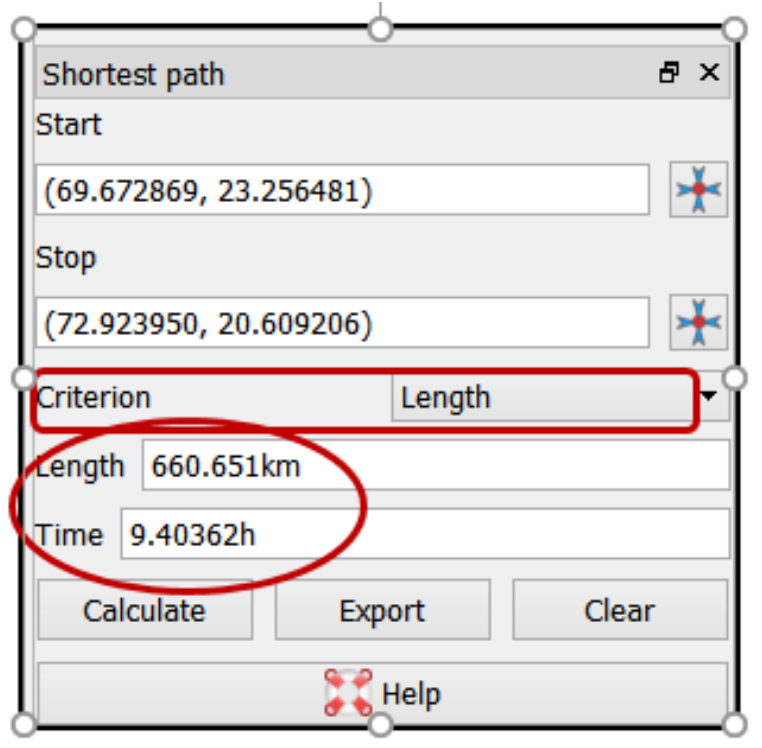

Fig. 9. Shortest path Tool 
or mobile Browser. WebGIS is technology to communicate between a server and a client.

WebGIS is having more advantages than the Traditional Desktop GIS. With the permalink users can access the map from either desktop or mobile devices. WebGIS can be accessed from any of the following Browsers like Internet explorer, Mozilla Firefox, Apple safari, Google Chrome, and so on. These browsers are in HTML and Java Scripts; it supports different operating systems such as Microsoft windows, Linux and Apple Mac Operating systems. WebGIS can be shared to many users, at the same time and they can work together from home, work place or in the field. WebGIS is very easy to use. WebGIS is meant for General users they not even know much about GIS. So WebGIS is designed to be very simple and convenient for the end users.

There are many methods available for WebMap publishing. In QGIS we have many plugins for map publishing. They are qgis2web, qgis2leaf, Geoserver Explorer, QGIS Cloud, NextGIS Connect. A comparative study is done, and after that selected NextGIS connect plugin for WebMap Publishing.

Functionalities of WebMap Interface:

- Layer Tree

- Layer Drop Down Menu (Description, Zoom to layer, Feature Table)

- Base layer Selection

- Zoom in and Out. Measure Distance, Area, Print

- Search, Identify

- Longitude, latitude, scale

- Share - Google Plus, Twitter, Facebook, Permalink.

- http://sandhya.nextgis.com/resource/902/display? base $=$ osmmapnik\&lon $=71.3108 \&$ lat $=22.4304 \&$ angl e=0\&zoom $=8 \&$ styles $=885,889,891,893,895,897,899$ ,901

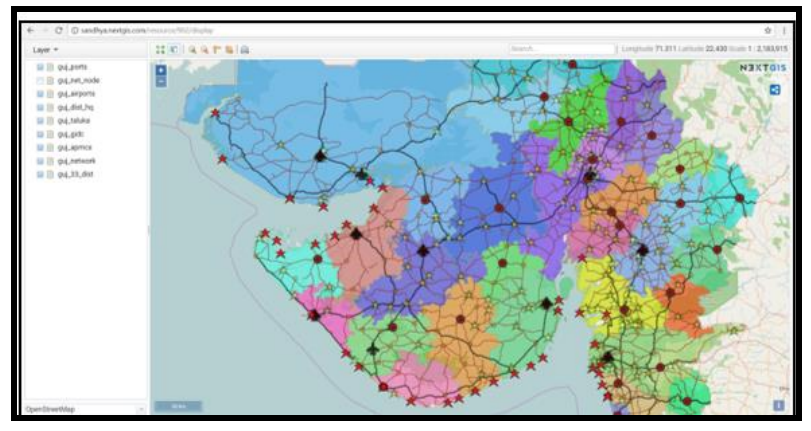

Fig. 12. NextGIS Web interface.

\section{RESULTS \& DISCUSSIONS}

In this study, randomly taken 15 Origin \& Destinations and calculated shortest Path using Road Graph and compared the result with Google Directions API Online Routing Mapper. Results of comparison confirm the feasibility and robustness of Road Graph Plugin for finding the shortest and fastest path, which shows its potential application in real road networks. And this system can be applied to any Road networks.
Road Graph used in QGIS is a simple and reliable tool for finding the shortest and the fastest path on a Road Network. It is easy to work with this tool. We don't need to do anything special to our polyline layer to route across it. As long as our polyline segments are all connected we can use it. For getting better result this tool should be configured correctly. It is important to verify the settings especially the length and time units and projection system before executing the analysis for getting proper results. We can assign a constant average speed for all road types or we can assign different speed limits for various Road Types. In this study only considered State Highways and National Highways. For getting more accurate paths we can incorporate all road types. (Expressways, Major District Roads and Other District Roads.

The NextGIS WebMap interface is pleasing and simple. It has functionalities to visualize Layer Tree, Layer drop down menu to see the feature tables and descriptions. There are options for zoom in and out. We can measure Distance and Area. We can search and identify any features. There is base layer on and off options. We can print the maps. We can even share our maps in social media i.e., Google Plus, Twitter, Facebook etc.

NextGIS is the latest Cloud Based Technology for sharing Geo spatial data. The Process is very simple. In NextGIS we can have both WebGIS Resource Page and WebMap Interfaces. By customization this interface can be made more interactive with adding Title and Description Panels and some basic Analysis Tools.

\section{CONCLUSIONS \& RECCOMENDATIONS}

This Research Study has presented on use of Open Source Desktop software QGIS and Web based NextGIS systems for Performing the Geospatial Applications and the Web Based Applications.

This study has shown that the open source software QGIS is Capable, Competent and Effective system for Creating, Storing, Editing, Displaying, Managing, Analyzing and Sharing Geospatial Data.

A cost effective GIS based solution were proposed for the Management, Planning and Monitoring of different Infrastructures.

This study recommends the need for greater awareness of Open Source GIS software for Establishment of GIS system in the coming future.

\section{FUTURE SCOPE}

The future scope of this study is to have a complete WebGIS with the following facilities.

- DATA Portal and Map Portal.

- Map layout with Title and Description Panels.

- Search, Query, Identify, Measure, Zoom in/out, Print, Share options.

- Thematic Maps Display

- District Map 
- Road Network Map

- Infrastructure Facilities Map (GIDC, Sea Ports, Airports, APMC's)

- Analysis Tools

- Proximity Analysis

- Network Analysis

\section{REFERENCES}

[1] Comparison of ArcGIs and QGIS for application of sustainable palnning. (2014). Retrieved from Friedrich, Corinna: http://othes.univie.ac.at/35758/

[2] AequilibraE - A Transportation Modelling toolbox for QGIS. (n.d.) Retrieved from www.aequilibrae.com

[3] Arora, N. (2016). Analysis of Petrol Pumps Reachability in anand District of Gujarat. International Journal of Computer Science and Bussiness Informatics.

[4] Asha Bhandari, A. p. (2016). Generation of Web based Geo information System at panchayat level of national Resources using Open source softwares's and libraries. international journal of science, engineering and Technology Research (IJSETR).

[5] Calculating shortest path in QGIs using Road Graph. (n.d.) Retrieved from http://gis-lab.info/qa/road-graph-eng.htm

[6] Geographic Information Systems (GIS) manage. (n.d.). Retrieved from http://www.manage.gov.in/studymaterial/GIS.pdf

[7] Get started with your WEBGIS. (n.d.). Retrieved from Nextgis.com http://docs.nextgis.com/docs ngcom/source/ngqgis connect.html

[8] Getting started With POSTGIS. (n.d.). Retrieved from http://bostngis.com/printerfriendly.aspx?content name=postgis tut 01
[9] How to manage data with desktop app Nextgis QGIS. (n.d.) Retrieved from nextgis.com: http://docs.nextgis.com/docs ngcom/source/ngqgis connect.html

[10] Jatin Pandey, D. P. (2011). GIS based Road Information System - a case study of 2010 Disaster in uttarakhand. Journal of Engineering Research studies.

[11] K.IIAYARAJA. (2012). Road Network analysis in Neyveli Township cuddalore District by using Quantum GIS. Indian Journa of Computer Science and Engineering.

[12] NextGIS Web Documentation Release 3.0. (n.d.). Retrieved from http://docs.nextgis.com/downloads/NextGIsWeb.pdf

[13] Prashanth Persai, S. K. (2015). Open source GIS and Cloud Computing Technology For the Power Distribution System. Journal of Geomatics.

[14] QGIS CLOUD. (n.d.). Retrieved from http://qgiscloud.com

[15] Satya Prakash Maurya, A. O. (2015). Open Source GIS Opportunities and challenges. Varanasi.

[16] Stefen Steiniger, A. J. (n.d.). Free and open source GIS for Software Building a Spatial data Infrastructure.

[17] Suresh S, D. M. (2015). Open source WEBGIS application for Decentralized planning. International Journal of Science and reserach(IJSR).

[18] The QGIS Road Graph Plugin. (n.d.). Retrieved from http://ghost.mixedbredie.net/the-qgis-road-graph-plugin/ 